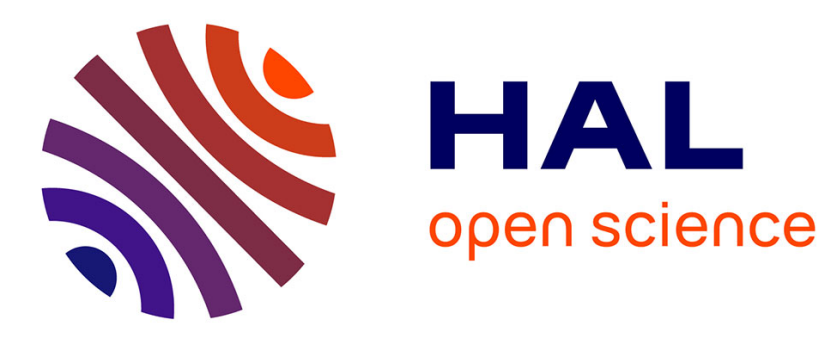

\title{
The Concordiasi Project in Antarctica
}

Florence Rabier, Aurélie Bouchard, Eric Brun, Alexis Doerenbecher, Stéphanie Guedj, Vincent Guidard, Fatima Karbou, V.H. Peuch, Laaziz El Amraoui, Dominique Puech, et al.

\section{- To cite this version:}

Florence Rabier, Aurélie Bouchard, Eric Brun, Alexis Doerenbecher, Stéphanie Guedj, et al.. The Concordiasi Project in Antarctica. Bulletin of the American Meteorological Society, 2010, 91 (1), pp.69-86. 10.1175/2009BAMS2764.1 . insu-00562459

\section{HAL Id: insu-00562459 https://hal-insu.archives-ouvertes.fr/insu-00562459}

Submitted on 14 Jan 2021

HAL is a multi-disciplinary open access archive for the deposit and dissemination of scientific research documents, whether they are published or not. The documents may come from teaching and research institutions in France or abroad, or from public or private research centers.
L'archive ouverte pluridisciplinaire HAL, est destinée au dépôt et à la diffusion de documents scientifiques de niveau recherche, publiés ou non, émanant des établissements d'enseignement et de recherche français ou étrangers, des laboratoires publics ou privés. 


\section{THE CONCORDIASI PROJECT IN ANTARCTICA}

by Florence Rabier, Aurélie Bouchard, Eric Brun, Alexis Doerenbecher, Stéphanie Guedj, Vincent Guidard, fatima Karbou, Vincent-Henri Peuch, Laaziz El Amraoui, Dominique Puech,

Christophe Genthon, Ghislain Picard, Michael Town, Albert Hertzog, François Vial, Philippe Cocquerez, Stephen A. Cohn, Terry Hock, Jack Fox, Hal Cole, David Parsons, Jordan Powers, Keith Romberg, Joseph VanAndel, Terry Deshler, Jennifer Mercer,

Jennifer S. HaAse, Linnea Avallone, Lars Kalnajs, C. Roberto Mechoso, Andrew Tangborn, Andrea Pellegrini, Yves Frenot, Jean-Noël Thépaut, Anthony McNally, Gianpaolo Balsamo, and Peter Steinle

The Concordiasi field experiment is making innovative atmospheric observations in Antarctica, in part with a constellation of stratospheric superpressure balloons deployed from the McMurdo station.

M OTIVATION. Concordiasi is motivated by the urgent need to reduce uncertainties in diversebut complementary-fields in Antarctic science. A critical issue for society is whether climate change can result in a significant change of the mass budget of the Antarctic ice sheet and consequently can affect global sea level. Reanalyses datasets are vital tools to assess the evolution in time of the precipitation distribution and other fields important to the mass

AfFiliations: Rabier, Bouchard, Brun, DoerenbeCher, Gued, Guidard, Karbou, Peuch, El Amraoui, and Puech-CNRM/GaMe (Météo-France and CNRS), Toulouse, France; Genthon, PICARD, and Town-LGGE, Grenoble, France; HeRTZOg and VIAL-LMD, Paris, France; CocQuerez-CNES, Toulouse, France; Сohn, Hock, Fox, Cole, Parsons, Powers, Romberg, and VanAndel一 NCAR, Boulder, Colorado; DeshleR AND MERCER-University of Wyoming, Laramie, Wyoming; HAASE-Purdue University, West Lafayette, Indiana; AVALLONE AND KaLNAJS-University of Colorado, Boulder, Colorado; MeCHOSO-UCLA, Los Angeles, Los Angeles, California; TANGBORN-GMAO, NASA GSFC, Greenbelt, Maryland; PellegrinI-PNRA, Rome, Italy; FrenOT—IPEV, Brest, France; budget over the ice sheet. Antarctica and the Southern Ocean are operationally and climatologically data sparse, even in comparison to the Arctic, as a result of highly limited surface-observing facilities in the high southern latitudes. Satellite measurements have the potential to fill these data gaps, but they present their own unique challenges and difficulties. This is particularly true of the data provided by hyperspectral infrared sounders, such as the Infrared Atmospheric

Thépaut, McNally, and Balsamo-ECMWF, Reading, United Kingdom; STEINLE-CAWCR, Melbourne, Australia CORRESPONDING AUTHOR: Florence Rabier, CNRM, $42 \mathrm{Av}$ Coriolis, 31057 Toulouse, France E-mail: florence.rabier@meteo.fr

The abstract for this article can be found in this issue, following the table of contents. DOI:10.1175/2009BAMS2764.I

In final form 20 July 2009

(C)2010 American Meteorological Society 
Sounding Interferometer (IASI) or the Atmospheric Infrared Sounder (AIRS). These challenges must be overcome, and errors need to be reduced to produce accurate reanalyses for climate studies that are based primarily on observed conditions. Accurate real-time analyses are also of importance for local weather forecasts (used in field operations) as well as for a better understanding of more global interactions between Antarctica and other regions.

The largest ozone depletion in the Earth's atmosphere occurs in the southern polar stratosphere. The decrease in stratospheric ozone observed since the 1980s (Farman et al. 1985) is perhaps the feature of the Antarctic climate that has attracted the most attention from the public and the scientific community. Although the role of polar stratospheric clouds in ozone depletion over the polar regions has been recognized for more than two decades, critical questions remain unanswered on the chemistry and microphysics of these clouds, such as the nucleation mechanism for nitric acid trihydrate (NAT) particles (e.g., Tolbert and Toon 2001; Larsen et al. 2004). Questions also linger on the interactions among these clouds and the dynamics of the southern stratosphere (e.g., Hopfner et al. 2006).

OVERVIEW OF THE PROJECT. Investigations of precipitation to constrain the mass budget over Antarctica and stratospheric ozone depletion provide strong motivation for improved multiscale, in situ measurements. The remoteness, harsh environmental conditions, and high elevations of the Antarctic plateau have made it difficult to base intensive field campaigns from locations on the continent. However, new opportunities have arisen that are at the core of the Concordiasi project. This is a multidisciplinary effort employing a constellation of long-duration instrumented stratospheric balloons as well as in situ observations at the Concordia $\left(75^{\circ} \mathrm{S}, 123^{\circ} \mathrm{E}\right)$ and at the Dumont d'Urville stations $\left(66^{\circ} \mathrm{S}, 140^{\circ} \mathrm{E}\right)$ on the coast of Adélie Land. The research plan includes investiga-
Antarctic area

Stratospheric super-pressure balloons

Flight level instruments

meteorological sensors

ozone sensors particle counter GPS receivers

Dropsondes radiosoundings and instrumented tower

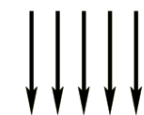 \\ $\downarrow$}

2009

2010

2011

ASI retrievals at Concordia Boundary layer studies nstrument preparation

$$
\begin{gathered}
\text { IASI retrievals at dropsonde locations } \\
\text { Evaluation of chemical transport models } \\
\text { Scientific studies based on stratospheric data } \\
\text { Data Assimilation studies using balloon data } \\
\text { Validation of satellite data assimilation using dropsonde data }
\end{gathered}
$$

FIG. I. Representation of the Concordiasi field experiment in time, data deployed, and scientific studies.

tions ranging from ozone transport and depletion, and microphysics of polar stratospheric clouds to the use of satellite data to improve operational analyses and reanalyses used for climate research. Concordiasi will also address the meteorology of the plateau, including clouds, precipitation accumulation, and the structure and dynamics of the boundary layer over Antarctica. Modeling investigations will be inherently multiscale, using high-resolution mesoscale models, numerical weather prediction systems, and global climate models. The modeling and observational datasets will result in collaborative efforts in satellite data assimilation, and in understanding Antarctic clouds and precipitation, the evolution of the stable boundary layer, and the interplay among polar stratospheric clouds, gravity waves, vortex dynamics, and ozone depletion.

Concordiasi is a joint French-United States initiative that started during the International Polar Year (IPY). The project takes place over Antarctica during September-November 2008, December 2009, and September-December 2010. Concordiasi is part of the IPY-The Observing System Research and Predictability Experiment (THORPEX; www.wmo.int/ thorpex) cluster of research activities endorsed by the International Council for Science-World Meteorological Organization (ICSU-WMO) panel. Participants include scientists from France, the United States, Italy, and Australia, as well as international organizations 
such as the European Centre for Medium-Range Weather Forecasts (ECMWF).

\section{OVERVIEW OF THE CONCORDIASI} EXPERIMENTAL DESIGN. An overview of the Concordiasi experimental design and associated scientific strategy is shown schematically in Fig. 1. The different project components are described next.

Surface-based measurements. Routine measurements are taken over Antarctica, mostly along the coast, except at the Amundsen-Scott research station on the South Pole (operated by the United States) and Concordia on the plateau at Dome C (operated by Italy and France). Amundsen-Scott performs two radiosoundings a day, and Concordia provides radiosoundings on the global telecommunication system (GTS) at 1200 UTC. Concordia was recently established, with a February 2005 starting date for a first winter stay of 13 technicians and scientists. Surface transport of heavy loads to Concordia from Dumont d'Urville takes 10-15 days. Concordia is ideally located to validate satellite data assimilation because the Antarctic plateau surface is extremely homogeneous compared to many other environments. For sun-synchronous satellites, such as Aqua and MetOp, the orbital inclination is generally around $98^{\circ}$. Thus, the pole itself is not directly under the satellite swath, although it is covered by the edge of swath, whereas Concordia Station is directly under the satellite path several times a day. During September-November 2008, the frequency of radiosounding at Concordia was increased to twice daily, making it similar to that at Amundsen-Scott, with special soundings synchronized with satellite overpasses. The frequency of soundings at Dumont d'Urville on the coast has also been increased. At Concordia, additional special radiosoundings will be made under intensive operating periods around December 2009 to document local weather conditions for more detailed clouds, precipitation, and boundary layer studies over the plateau.

In addition to the soundings, specific instruments for meteorological, snowfall, and accumulation observations have been deployed at Concordia by the Laboratoire de Glaciologie et Géophysique de l'Environnement (LGGE) with support from the Institut Paul Émile Victor (IPEV), the Institut Polaire Français (French Polar Institute), and the Institut National des Sciences de L'Univers (INSU). In particular, six levels of meteorological observations of wind, moisture, and temperature were deployed on a $45-\mathrm{m}$ tower.
Stratospheric superpressure balloons (SPBs). The Concordiasi field campaign will launch a constellation of up to 18 long-duration stratospheric balloons from the McMurdo station of the U.S. National Science Foundation (NSF) by the Centre National d'Etudes Spatiales (CNES, the French space agency) in 2010. Similar stratospheric balloon systems have been extensively used for atmospheric research. In the southern spring of 2005, the Vorcore project deployed a constellation of 25 CNES stratospheric balloons from McMurdo $\left(78^{\circ} \mathrm{S}, 166^{\circ} \mathrm{E}\right)$. The balloons drifted on isopycnal surfaces in the lower stratosphere and gathered meteorological data at 15-min intervals (Hertzog et al. 2007). The average flight duration of these balloons was 58.5 days, with the longest flight lasting 109 days.

Vorcore's scientific results include a better knowledge of the gravity wave field in the lower polar stratosphere, the dispersion regime inside the polar vortex, and an assessment of the accuracy of analyses in the polar region by operational centers (Vincent et al. 2007; Boccara et al. 2008; Hertzog et al. 2008; Plougonven et al. 2008).

The potential of Vorcore-type balloons as research platforms is increasing rapidly because of revolutionary developments in computational hardware, global positioning, and communication, together with the development of low-power, miniature sensors. The balloons used in Concordiasi will have major improvements over those used in Vorcore. An upgraded communication system will allow for an increased frequency of meteorological observations at flight level from 15- to 1-min intervals, which improves the resolution of dynamical features such as highfrequency gravity waves. Six of the Concordiasi flights will be dedicated to chemistry and microphysical missions. These balloons will be launched during August and September 2010 and will be designed for 4-month durations. The Laboratoire de Météorologie Dynamique (LMD) in France is developing a small lightweight sensor that is able to measure ozone in these flights. Some balloons will carry the University of Colorado's light-emitting diode (LED)-based UV ozone photometer. Four of these balloons will include measurements of polar stratospheric clouds using particle counters developed by Terry Deshler's group at the University of Wyoming.

Two of the CNES balloons will be upgraded to carry high-accuracy, dual-frequency GPS receivers developed at Purdue University. Such receivers have the potential to produce GPS radio occultation profiles of refractivity, from which temperature and humidity profiles can be derived. GPS radio occulta- 
tion was first developed for receivers on low-earthorbiting satellites, which record refracted signals from higher-orbit GPS satellites as they set behind the earth's limb (Kursinski et al. 1997). The technique has also been implemented in high-altitude research aircraft (Garrison et al. 2005). Isopycnal balloon platforms are particularly well adapted to this type of observation because the accuracy of the observation increases for higher-altitude receivers. The measurements can continue for the entire duration of the flight, providing a wealth of data. The refractivity is expected to be of great value for research and for baseline comparisons to test satellite data assimilation in the numerical models for the Antarctic region. The best-case scenario would provide an average of about two occultation profiles per hour for each balloon poleward of $60^{\circ} \mathrm{S}$, where normally there are about 20 soundings per day.

Concordiasi will further extend the concept of moving beyond a flight-level research platform by launching up to 12 balloons that carry gondolas called driftsondes in September and October 2010. The gondolas hold instrument packages that descend by parachute. Each driftsonde carries up to 50 miniature GPS dropsondes that can be released upon command, falling from the balloon flight level to the surface while producing a high-resolution vertical profile of temperature, humidity, winds, and pressure. Similar GPS dropsondes are extensively deployed from aircraft for research and operational prediction. For example, the prediction of hurricane tracks and intensity rely on data from dropsondes deployed from aircraft. The driftsonde has been successfully flown on CNES stratospheric balloons during the 2006 hurricane season for flights over Africa and the tropical Atlantic (Drobinski et al. 2006). Most recently 13 driftsondes were flown in the 2008 THORPEX Pacific Asian Regional Campaign (T-PARC) and provided several hundred atmospheric profiles from the lower stratosphere to the surface over the data-sparse tropical Pacific.

The driftsonde is being modified to meet the requirements of Concordiasi and to improve its performance based on experience from T-PARC. Flight durations during Concordiasi will be at least six weeks long compared to the roughly weeklong flights in previous projects, and there will be more than 10 driftsondes aloft at the same time. Changes for Concordiasi include using more batteries and adding solar panels to meet the power and heating requirements, altering the sonde release process for more reliability, and improving the software interface to simplify operations and allow for many driftsondes aloft at once.
In Concordiasi, the dropsonde releases will be mainly targeted at IASI and AIRS satellite overpasses to validate the assimilation of satellite data. However, some dropsondes will be devoted to predictability studies, as will be described later in this paper. Dropsondes will also be used to validate the GPS instruments.

Antarctic treaty and data policy. Prior to the Concordiasi's implementation, an initial environmental evaluation (IEE) was conducted according to the directives of the Antarctic Treaty Protocol for protection of the environment, the so-called Madrid Protocol, and in particular the directives in annex I on evaluations of environmental impact. The study was undertaken because the planned activity included the discarding and diffusion of a minimal amount of waste on the Antarctic continent or in the Southern Ocean. On the basis of this IEE, the French competent authority, Administrateur Supérieur des Terres Australes et Antarctiques Françaises, delivered the authorization for conducting this experiment in Antarctica (Arrêté 2008-105, signed 6 October 2008).

Radiosonde data are being made available in real time on the GTS, together with dropsonde and some in-flight data (wind and temperature observations at gondola level). Other data will be made available as they are processed, with an expected delay of six months and a maximum delay of two years after measurement, according to IPY data policy. (Data can be accessed at www.cnrm. meteo.fr/concordiasidataset/.)

Modeling component. In addition to the observational component, Concordiasi comprises an extensive modeling and data assimilation effort. Météo-France will conduct global and high-resolution regional simulations. The French global Model, Action de Recherche Petite Echelle Grande Echelle (ARPEGE), which means "research project on small and large scales" (e.g., Fourrié et al. 2006), developed in collaboration with ECMWF, uses four-dimensional variational assimilation (4DVar) and has been adapted to have a higher spatial resolution over Antarctica. The French limited-area nonhydrostatic mesoscale model (Meso$\mathrm{NH}$ ), or its numerically efficient version Applications of Research to Operations at Mesoscale (AROME), will be nested in ARPEGE, with a grid as fine as $2.5 \mathrm{~km}$. Real-time mesocale forecasts will also be produced by the Weather Research and Forecasting model (WRF) with the Antarctic Mesoscale Prediction System (AMPS; Powers et al. 2003), run jointly by the National Center for Atmospheric Research 
(NCAR) and The Ohio State University. AMPS provides numerical weather prediction (NWP) support to the U.S. Antarctic Program (USAP) and a host of other nations working in Antarctica.

The high-resolution regional models are valuable tools for addressing many processes critical to the climate system over the Antarctic region, such as vertically propagating gravity waves that can influence stratospheric clouds, orographically induced circulations, and mesoscale vortices that result in intense precipitation events. Furthermore, the sophisticated boundary layer parametrization and microphysics included in the mesoscale models will help to better describe tropospheric clouds and fog. The global models will be used to investigate the teleconnections between Antarctica and other regions. A better understanding of these links will support efforts to improve parameterizations of critical physical processes in coarse-grid models. The French modeling effort will also have a strong data assimilation component aimed at improving the analysis and reanalysis products over Antarctica. The validation of model products at finescale will be performed primarily at the LGGE (Genthon et al. 2005; Krinner et al. 2006) using local field observations. The effect of improvements in the atmospheric general circulation on the simulations and predictions of ozone profiles will also be assessed using a chemical-transport model.

\section{SCIENTIFIC GOALS. Satellite data assimilation.}

The science goals of Concordiasi require observations and analyses of the atmosphere at various time scales. Analyses can be used as initial conditions for real-time forecasts, which can then be used to better understand and predict polar meteorology, particularly in support of operations in the polar regions. For climate research, reanalyses by operational centers are powerful tools for the documentation of past atmospheric conditions. The construction of analyses and reanalyses relies on numerical models, and the fields produced by these models can be used for a variety of purposes, including the derivation of parameters in poorly sampled areas, the definition of relationships between variables and their variations in space and time, and the detection of errors in the observations. The general goal of data assimilation, particularly for investigations on the climate record, is thus to incorporate as much useful data as possible to avoid drawing conclusions that are model dependent. Over Antarctica, the scarcity of conventional observational data needs to be compensated by satellite information, particularly from those devices in a polar orbit.
Previous studies have shown that satellite data have a much larger effect on forecasts and reanalyses in Antarctica than in other data-richer areas, such as the Arctic. Satellite data have had significant effect and success in use in data assimilation (Bouttier and Kelly 2001), especially since more advanced data assimilation techniques have been implemented, such as 4D-Var (Rabier et al. 2000). However, challenges remain, and the use of satellite observations still needs to be optimized. The optimization of the use of satellite data within data assimilation is one of the issues tackled by the international program THORPEX (Rabier et al. 2008). This optimization is particularly needed for the new generation of advanced hyperspectral sounders, such as AIRS on Aqua, IASI on MetOp, and the future Cross-Track Infrared Sounder (CrIS) on the National PolarOrbiting Operational Environmental Satellite System (NPOESS; e.g., Fourrié and Rabier 2004). These new instruments, measuring in the infrared, provide information on atmospheric temperature and humidity profiles, trace gases, and surface properties.

Key problems in the successful assimilation of advanced sounders over the polar regions are cloud detection and distinguishing the surface contribution to the measured signal. As an example, clouds over very cold surfaces in a stable atmosphere appear warmer in infrared data compared to the underlying surface. This signal is the opposite of that expected in most cloud detection schemes over warmer surfaces. Furthermore, polar stratospheric clouds can alias atmospheric temperature signals because they are difficult to detect. However, channels with weighting functions that peak high in the atmosphere can be used in these cases to minimize biases caused by clouds. Figure 2 shows an example of the additional data coverage used in an experimental data assimilation suite in ARPEGE, compared to the operational use of IASI, for the lowest IASI channel used over sea ice and land, peaking at about $300 \mathrm{hPa}$. This additional data coverage resulted in improved forecasts over the Antarctic area, the beneficial effect extending in time over more extended southern latitudes. But this is a first step only, as we now want to extend the use of radiances to channels peaking lower down. Before tackling the difficult subject of cloud detection over polar areas, we will concentrate on surface issues in areas where clouds are not too frequent by performing detailed investigations of retrievals over Concordia, where we will benefit from the extra radiosoundings.

The issue we want to investigate is the significant variability of the polar surface. The temperature and 


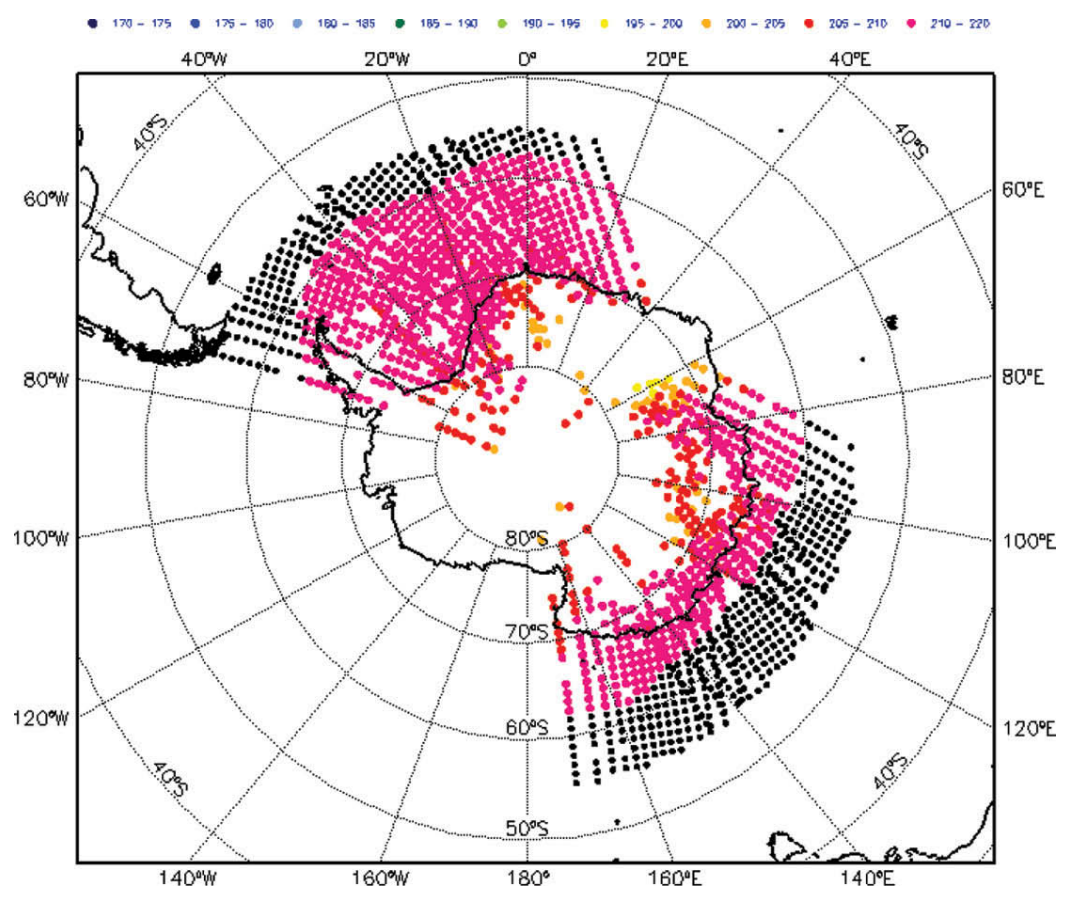

FIG. 2. Use of IASI data (channel 306) over the Antarctic region, for an experimental suite using IASI over land and sea ice for high-peaking channels, for a 6-h period. Locations of the assimilated pixels are indicated by circles. Black indicates that the observations were used operationally as well. Other colors indicate that these pixels were used only in the experimental suite. (They correspond to the brightness temperature of the measurement from 170 to $220 \mathrm{~K}$, with a step of $5 \mathrm{~K}$.) over surfaces associated with low surface emissivity, such as snow. In fact, snow significantly scatters microwaves (Zwally 1977), and a specular assumption for the surface may introduce biases for observations from scan-track instruments, such as Advanced Microwave Sounding Units A and B (AMSU-A and AMSU-B, respectively). To study the sensitivity of surface properties in retrievals, land surface emissivities at AMSU window frequencies have been calculated using specular, Lambertian, and intermediate surface reflections. It was found that emissivities derived at $50 \mathrm{GHz}$ and from observations close to nadir are rather sensitive to assumptions about the surface. Simulations of brightness temperatures at sounding channels were made and were compared with observations. For the simulations, the land surface emissivity at the closest window channel, in frequency, were assigned to each emissivity of the snow surface in heterogeneous regions can introduce significant biases and errors in atmospheric temperature retrievals because channels designed to provide temperature information in the midtroposphere still have a $10 \%$ sensitivity to surface conditions (English 2008). Thus, errors in modeling surface emission in these channels can be harmful in the retrieval of a useful atmospheric signal. In parallel, studies are being performed on how to improve the estimation of microwave emissivity over Antarctica, following the approach developed in Karbou et al. (2006). Feasibility studies have also been undertaken to improve our knowledge of the variability of surface emissivity over Antarctica. Surface emissivity retrievals in these studies make several assumptions about surface conditions. For example, the land surface emissivity is usually derived from satellite observations, assuming that the surface is flat and specular (Prigent et al. 1997, 1998, 2000; Prigent and Rossow 1999; Choudhury 1993; Jones and Vonder Haar 1997; Karbou et al. 2005; Morland et al. 2000, 2001; among many others). The specular assumption has been found valid for snow-free conditions (Karbou and Prigent 2005). Matzler (2005) questioned the use of the specular assumption for nadir viewing observations sounding channel. For instance, emissivities derived at $50 \mathrm{GHz}$ were assigned to AMSU-A temperature channels (50-60 GHz) and emissivities derived at $89 \mathrm{GHz}$ were assigned to AMSU-B humidity channels. It was found that the best results are obtained when the surface is assumed to have $50 \%$ specular reflection and 50\% Lambertian reflection (Guedj et al. 2009). Figure 3 shows the correlations between observations and simulations for AMSU-A channel $4(52.3 \mathrm{GHz})$. Results are plotted for August 2007 for the following experiments: a control experiment; an experiment that uses land surface emissivities, assuming the surface to have specular reflection; an experiment that uses land surface emissivities, assuming the surface to have Lambertian reflection; and an experiment that uses land surface emissivities, assuming the surface to have specular reflection and Lambertian reflection (50\% each). In the control experiment, the land surface emissivity was estimated using the empirical version of Grody (1988) and Weng et al. (2001) models for AMSU-B and AMSU-A observations, respectively. To provide emissivity estimates that meet numerical weather prediction requirements, the nonparametrical version of these models require input parameters for the surface, such as the roughness content, that 
are not available on a global scale. Observations and simulations correlate much better after inclusion of a surface emissivity that varies in space and time. The highest correlation is obtained for the mixed specularLambertian reflection (Fig. 3, bottom-right panel). More in-depth studies are planned to examine the effect of even more realistic descriptions of Antarctic surface emissivity on analysis and forecast skill.

To take advantage of these new infrared and microwave developments, a new assimilation suite, using additional data of both AIRS and IASI, and AMSU-A and AMSU-B, has been tested. Scores over the Southern Hemisphere show a better model performance (Fig. 4). The short-range forecasts of this tuned model have been compared to the extra radiosoundings de-
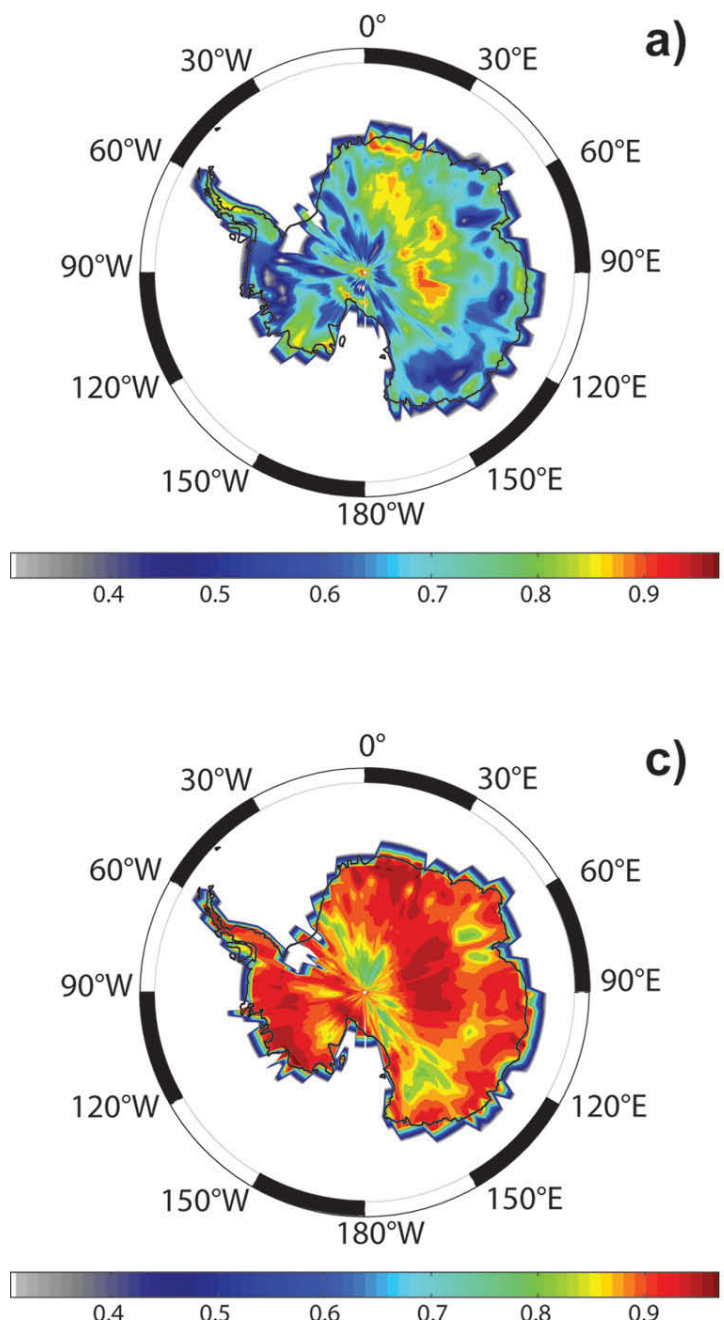

ployed at Concordia in September-November 2008 at 0000 UTC. Figure 5 shows statistics of temperature (left-hand panel) and humidity (middle panel) profiles for the model fields and the radiosonde and the Synoptic Ocean Prediction (SYNOP) observations at Concordia, averaged at 0000 UTC between 15 September and 30 November 2008 (70 profiles). The short-range forecasts from the model are indicated by circles and the observations by stars. The right-hand panel in the figure also shows the average ozone profiles for the period, as analyzed by the Modèle de Chimie Atmosphérique à Grande Echelle (MOCAGE) chemical-transport model (Massart et al. 2007). A maximum of ozone of $6.5 \mathrm{ppmv}$ can be observed around $7 \mathrm{hPa}$. These ozone profiles will be
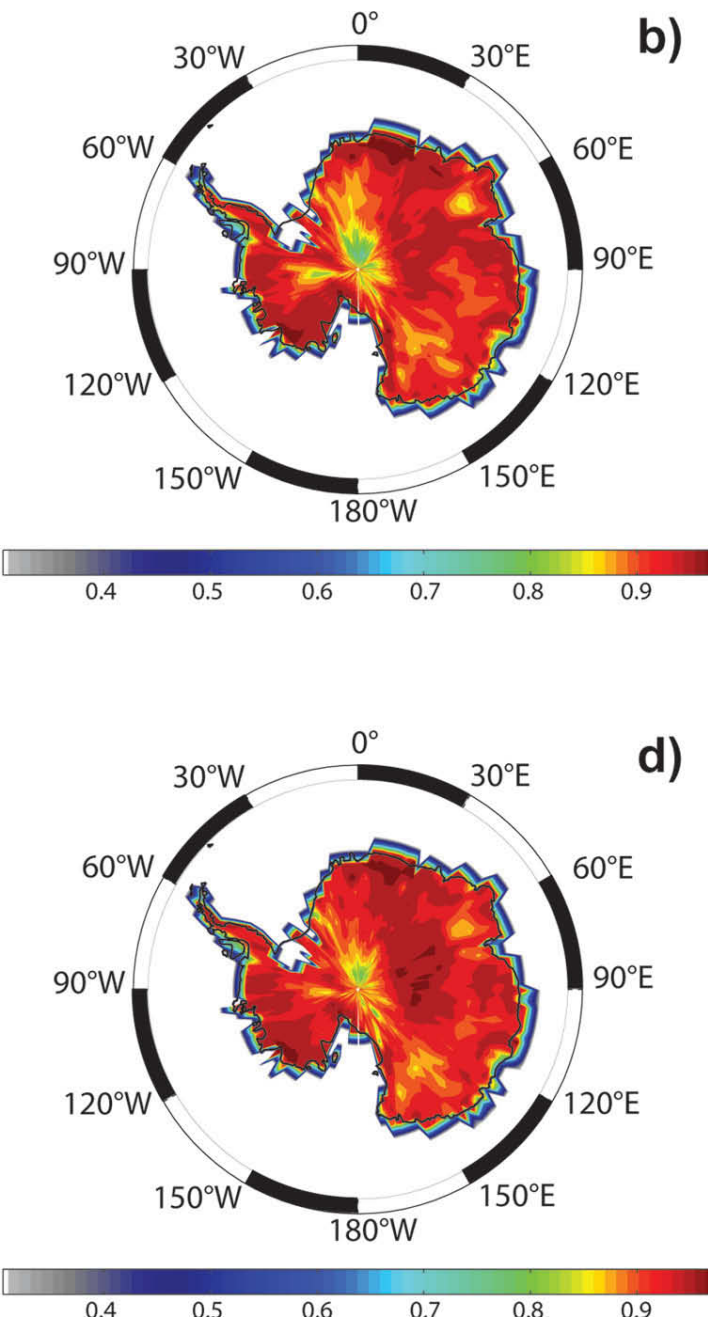

FIG. 3. Map of correlations between observations and simulations of AMSU-A channel 4 (52.3 GHz) for Aug 2007. Results are shown for (top left) a control experiment, (top right) an experiment in which the land surface emissivity has been estimated assuming the surface to have Lambertian reflection, (bottom left) an experiment in which the land surface emissivity has been estimated assuming the surface to have specular reflection, and (bottom right) an experiment in which the land surface emissivity has been estimated assuming the surface to have specular and Lambertian reflection ( $50 \%$ each). The correlations have been computed, taking into account data falling in a grid cell of $2^{\circ} \times 2^{\circ}$ size. 


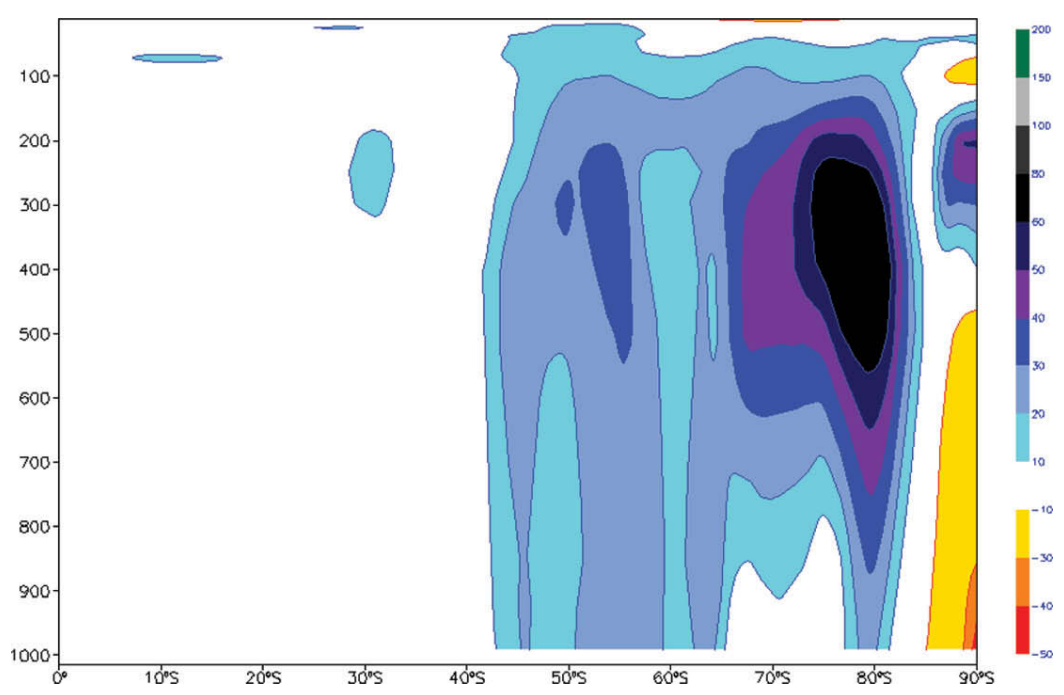

FIG. 4. Statistics of the differences in RMS errors between a version of the ARPEGE model assimilating the same observations as in operations and a version of the model using more satellite data over Antarctica. The statistics are shown for the geopotential errors of the 72-h forecasts over a period of three weeks in Jul 2007, averaged longitudinally. The vertical scale is pressure and the horizontal scale is latitude. Blue (yellow) indicates that the additional AIRS, IASI, and AMSU observations over Antarctica have improved (degraded) the forecasts.

used in radiative transfer calculations. Good agreement is seen between the model fields and the observations for the temperature field, except at the surface level when comparing the model surface temperature to SYNOP observations. There, a warm bias exists in the model (224 K versus $220 \mathrm{~K}$ ). For relative humidity, radiosonde observations are much drier than model fields at lower levels but moister in the stratosphere around $100 \mathrm{hPa}$. A similar behavior has been found in the troposphere for the ECMWF model (as will be shown in Fig. 8). At $400 \mathrm{hPa}$, the ECMWF model is moister than the radiosonde by about $20 \%$, which is equivalent to the moist bias seen for the ARPEGE model.

How does this translate in terms of fit to IASI observations? For each radiosonde observation at Concordia at 0000 UTC during this period, a IASI pixel was selected on the basis of proximity in space and time. Then, the radiative transfer model was run from either the radiosonde profile or the ARPEGE short-range forecast profile and compared to the IASI spectrum. Statistics of IASI spectra and the differences between simulated and IASI spectra at Concordia, averaged between 15 September and 30 November 2008, at 0000 UTC (70 spectra) are shown in Fig. 6. The top panel represents the averaged spectra for the IASI pixels, for a subset of 294 channels (from absolute channel numbers 16 to 6003 , corresponding to the wavenumbers $\left.648.75-2145.5 \mathrm{~cm}^{-1}\right)$. The middle and bottom panels represent the bias and root-mean-square of the differences between simulated spectra and IASI spectra, respectively. The simulated spectra use either the radiosonde profiles as inputs (solid lines) or the model short-range forecasts as inputs (dashed lines) for temperature and humidity. For surface fields (temperature and humidity), they come either from a synoptic observation (for the radiosonde simulation) or from the
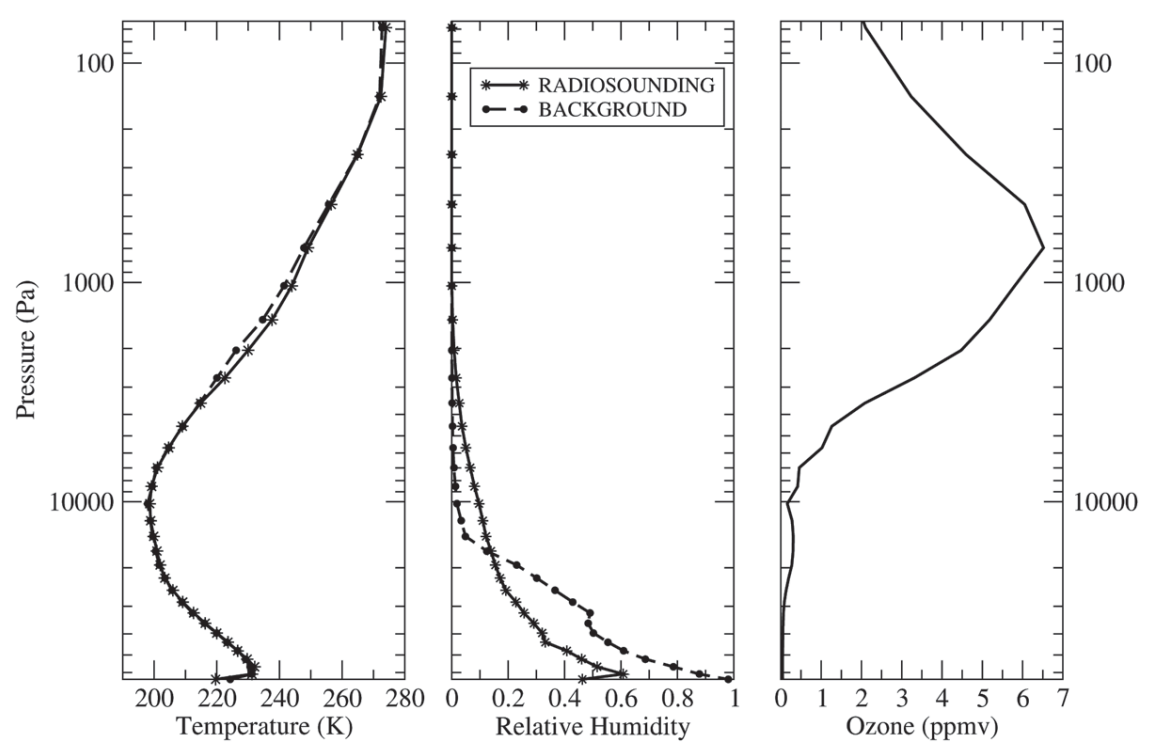

FIG. 5. Statistics of (left) temperature (K) and (middle) humidity (\%) profiles for the atmospheric ARPEGE model and the radiosonde observations at Concordia, averaged between 15 Sep and 30 Nov 2008 at 0000 UTC (70 profiles). The short-range forecasts from the model are indicated by circles and the observations by stars. The right-hand panel shows the average ozone (ppmv) profiles for the period as analyzed by the MOCAGE chemical transport model. The height is indicated in pressure $(\mathrm{Pa})$. 
model. Both simulations use ozone profiles as analyzed by MOCAGE. The simulations use the Radiative Transfer for Television and Infrared Observation Satellite Operational Vertical Sounder (RTTOV) model with coefficients derived from the kCompressed Atmospheric Radiative Transfer Algorithm (kCARTA) line-by-line model, a surface emissivity of 0.99 , and assume that no clouds are present.

The IASI spectrum shown here is relatively flat; the temperature profiles are quite cold and less contrasted than at other latitudes. The first part of the average spectrum shows variations linked to the main $\mathrm{CO}_{2}$ band and emission at various heights in the atmosphere. From 800 to $950 \mathrm{~cm}^{-1}$, the spectrum is mainly sensitive to surface properties. At around $1050 \mathrm{~cm}^{-1}$, there is a corresponding emission from ozone. Around $1500 \mathrm{~cm}^{-1}$, the spectrum is quite variable, showing the absorption/emission lines of water vapor. In the middle and bottom panels, the correspondence between the simulated spectra from radiosonde profiles and IASI spectra is quite good, with errors generally less than $4 \mathrm{~K}$ (solid lines). There is a small bias of the order of 1-2 K for surface channels, which could come from a warm bias in the input surface fields or could correspond to absorption/emission from clouds, which are not taken into account in the simulations. There was quite a high probability of clouds at Concordia during this period, based on cloud occurrence estimated from surface-based radiation measurements using a method developed by Town et al. (2007). The issue of clouds will be further investigated in the future. In contrast to the results obtained with radiosonde profiles, the model fields produce IASI simulated spectra that are too warm, mainly for surface channels, and less accurate in the water vapor band (dashed lines). An explanation for this could be the warm bias in the model surface temperature, as seen in the previous figure, and the overestimation of relative humidity.

This first evaluation of the IASI data with radiosonde observations from the first part of the campaign is quite encouraging. It suggests that we can rely on radiosonde observations and on radiative transfer models to simulate IASI spectra. It will be used as a basis to progress on the retrieval of parameters from IASI and on data assimilation with IASI and to understand issues in model biases, cloud effects, and data assimilation procedures based on in situ data and collocated IASI measurements. The comparison between radiosonde profiles and 0000 and 1200 UTC (not shown) showed the presence of a diurnal cycle, which will be further documented in austral spring 2009 with intensive radiosonde soundings and routine measurements from the instrumented tower at Dome C.

Model improvement. A critical component of Concordiasi is the better understanding and prediction of clouds and precipitation accumulation over Antarctica. A substantial amount of work will focus on the plateau region, but significant effort will also target coastal regions where mean annual precipita- 


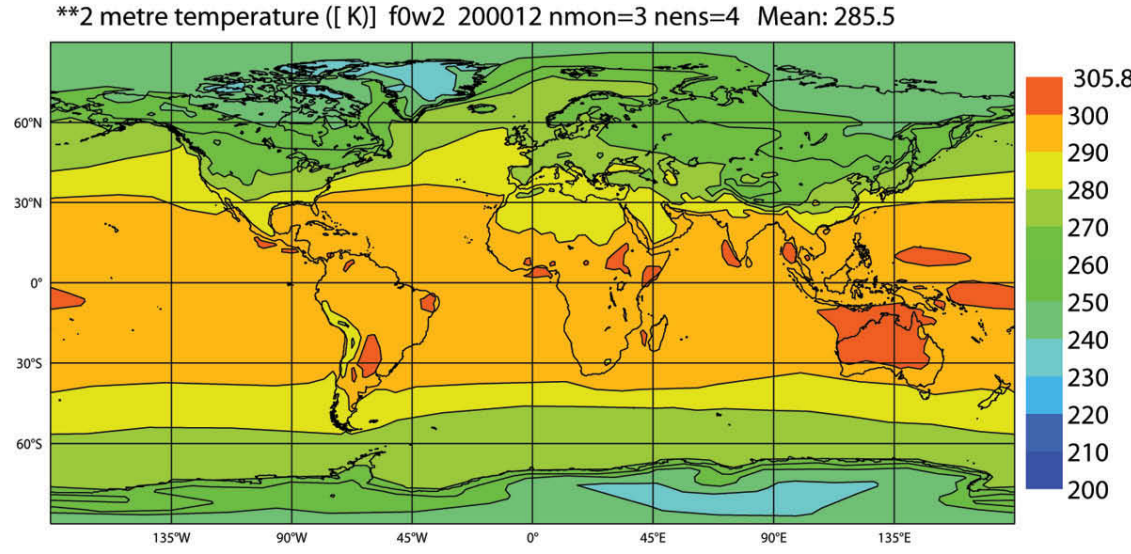

**2 metre temperature ([K)] fOwp 200012 nmon=3 nens=4 Mean: 285.7
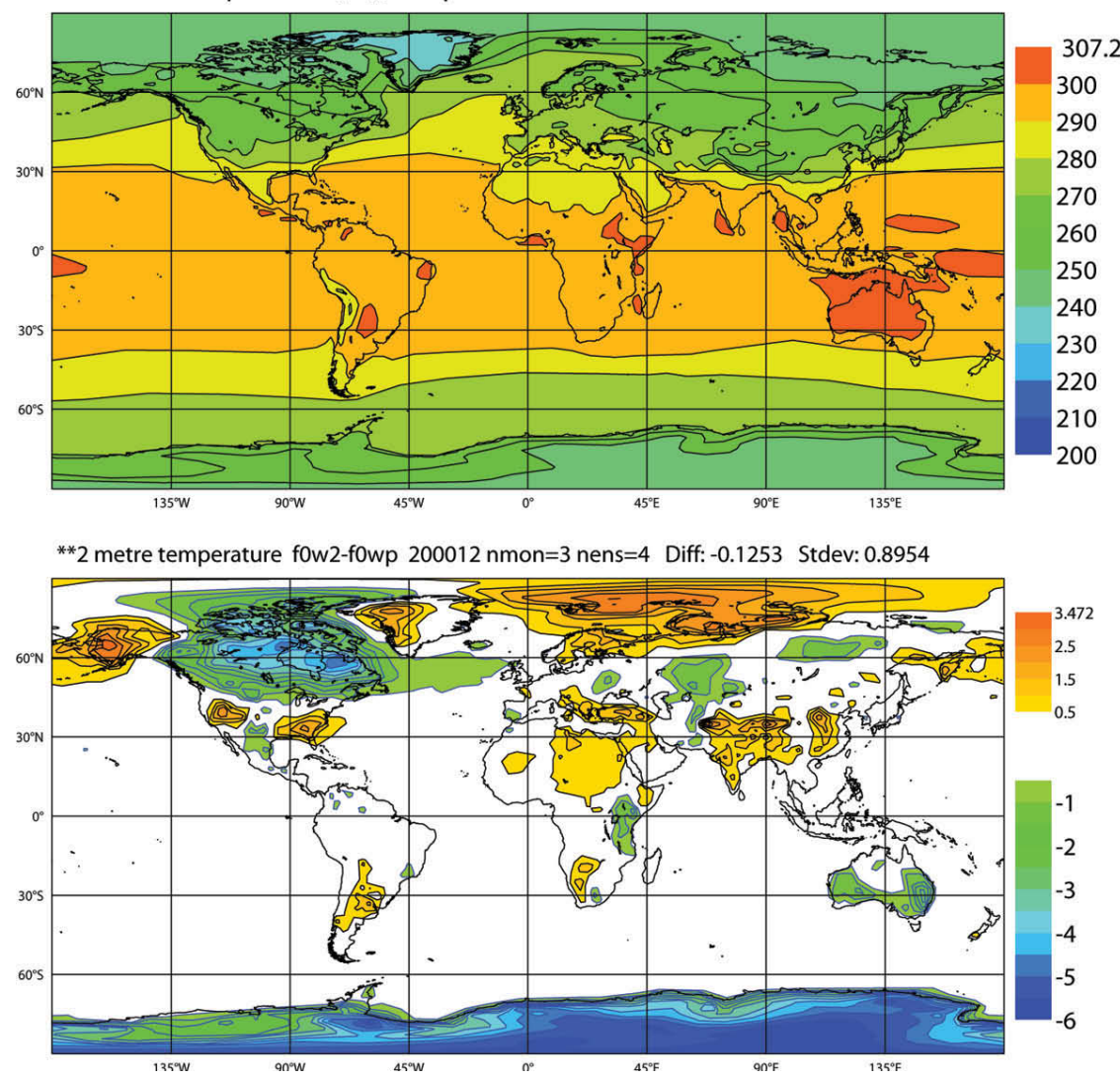

FIG. 7. Maps of the ECMWF model's skin temperature (K), averaged over a year starting on I Aug 2008 and over four members of an ensemble of simulations at TI59L9I resolution with ERA-40 specified sea surface temperature. (top) The averaged skin temperature with an operational version of the ECMWF model in 2008, (middle) the modified permanent snow albedo as introduced later, and (bottom) the difference between the two. process (Genthon et al. 2005). This work will use high-resolution models and in situ measurements at Concordia and coastal Adélie Land. The analysis of results from the multiscale model approach will suggest ways to improve the simulation of cloud and precipitation-related processes. It is expected that a better use of satellite data in the large-scale model together with detailed physical parameterizations in the finescale model coupled to the large-scale model will provide state-of-theart cloud and precipitation estimates. Optimizations of the assimilation will aim at further improving these predictions. In situ data will also help to diagnose model deficiencies. One of the first results of the combined analysis of data and model fields was the improvement of the ECMWF model over Antarctica that was performed in 2008 . Indeed, the comparison of the ECMWF model with measurements from the Dome C site highlighted a warm bias in the Antarctic model lower troposphere, affecting operational forecasts and reanalyses. This finding led to a modification of the albedo over permanent snow, with a clear beneficial effect during December-February and to a lesser extent during Junetion is larger and the effects of climate change are expected to be strongest (Genthon et al. 2009). The characterization of the interannual variability of Antarctic precipitation in the 40-yr ECMWF Re-Analysis (ERA-40) improved dramatically at the end of the 1980s with the advent of meteorological satellites and the use of their information in the data assimilation
August. Figure 7 shows the average skin temperature from the ECMWF before and after the change. A major effect can, indeed, be noticed over Antarctica. The performance of the model is now quite satisfactory over Concordia, as shown in Fig. 8, showing departures from the radiosoundings obtained during the first stage of the Concordiasi campaign. The 
temperature bias at the lowest radiosonde level is now less than $1 \mathrm{~K}$.

Predictability studies, effects on lower latitudes. One of the major goals of Concordiasi is the improved prediction of weather events over the southern polar regions and a better understanding of the predictability of such events. For the midlatitudes, it has been shown that the addition of "targeted" in situ data based on predictability information can result in higher forecast skill [e.g., the Winter Storm Reconnaissance Program (WSRP); Szunyogh et al. 2002]. The general concept is to enhance data gathering in regions where increases in the analyses' accuracy (e.g., the quality of initial conditions) have large payoffs in terms of improving predictions from those initial conditions. Can we apply this technique to the polar regions? It seems likely because the approach has been shown to have larger effects in data-sparse regions when initial conditions are poorly defined. The driftsonde observations are ideally suited for experimentation in this context. Meteo-France/CNRM plans to gather information about predictability from a version of the ECMWF Ensemble Prediction System focused on the higher latitudes in collaboration with ECMWF and to deploy observations in the sensitive areas as well as quite evenly, and then compare the results of assimilation of targeted observations in sensitive areas with results of assimilation of uniform observations.

Recent adaptive observation campaigns have used either dedicated observing platforms or opportunity platforms. Research aircraft are typical dedicated platforms, with nearly full control of the deployment of supplementary data. Research aircraft data are used in the WSRP, for example. However, such dedicated platforms come at a high cost. Routine observing platforms (e.g., radiosounding stations) that are switched on/off when requested outside

Concordia

15 SEP-30 NOV 2008

$90 \mathrm{~S}-180 \mathrm{~W} / 90 \mathrm{~N}-180 \mathrm{E}$

00/06/12/18 UTC uncorrected data combined
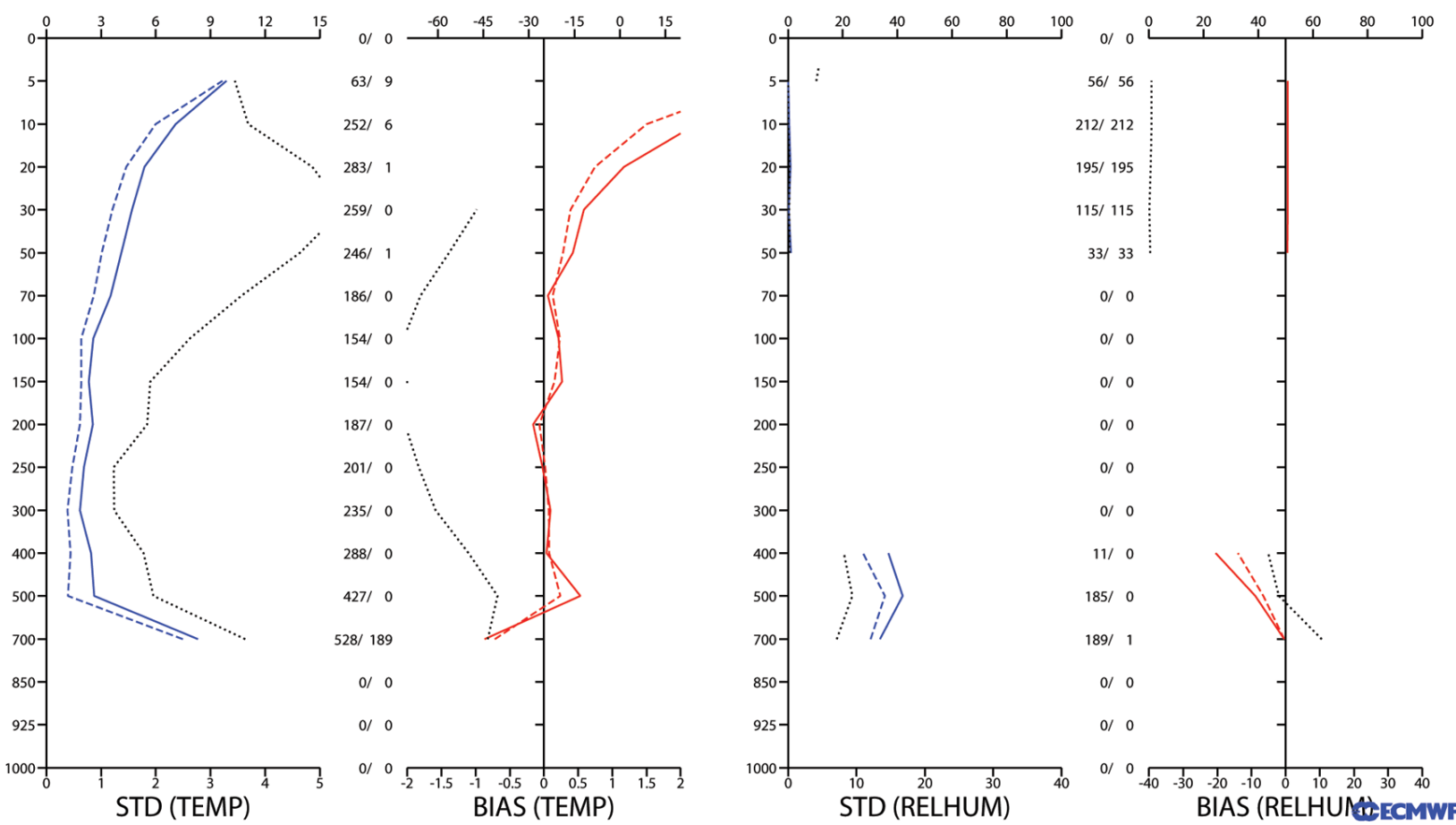

FIG. 8. Averaged differences between the sounding profiles for Concordia station and the ECMWF short-range forecast and analyses, over the period 15 Sep-30 Nov 2008: (left) temperature and (right) humidity. The differences between observations and short-range forecasts are shown in solid lines, and the differences between observations and analyses in dashed lines. Bias and standard deviation are shown in red and blue, respectively. The dotted lines are the mean observation (bias plot) and variability (std plot). The axis for the dotted lines is at the top of the plots. Those profiles were computed for the raw data (uncorrected for temperature and humidity) using standard and significant levels. The number of data used in the computation is indicated in the central columns of the plots. 
their regular observing period have played the role of opportunity platforms during the North Atlantic THORPEX Regional Campaign (NA-TReC) in 2003 (Leutbecher et al. 2004; Mansfield et al. 2005) and during the Data Targeting System (DTS) in 2008. Driftsondes represent a trade-off between these two approaches. Though the balloon drift cannot be controlled, the polar vortex and the significant number of deployed balloons yields a temporary additional in situ observing system dense enough to play the role of an efficient adaptive network. In view of the properties of the adaptive observing network, it is not worth chasing specific weather events with the targeting procedure implemented in Concordiasi. Hence, the domain of interest is first the polar cap, then second the lower latitudes (Australia/Tasmania). The sampling strategy will activate the balloons flying above high-sensitivity values, even if the maximum sensitivities of the day are elsewhere and cannot be overflown by balloons. The planned overall sampling strategy is to deploy approximately a third of the dropsondes above sensitive areas around 1800 UTC and the remaining twothirds of the dropsondes are deployed under satellite overpasses at other times of the day. The dropsonde deployment will take place during a period of a few weeks, starting in September 2010.

Sensitive areas were derived from singular vectors (Buizza and Palmer 1995) with a 1-day optimization period. Over Antarctica, the sensitive areas are located at the border of ice-covered regions, which correspond to the domain of interest for the Concordiasi study. This sensitivity can be explained by the maximum Eady growth rate (Hoskins et al. 2000) in locations further north than the $60^{\circ} \mathrm{S}$ limit. Singular vectors are known to roughly mimic that field when they are not geographically constrained, such as in the present computations. One can expect that with a longer optimization period (which is one day here), these sensitive areas would get closer to the Eady growth rate field and stretch farther north. Experience with analyzing major numerical forecast errors at the Australian Bureau of Meteorology has shown the subpolar latitudes $\left(55^{\circ}-70^{\circ} \mathrm{S}\right)$ to be a major source of errors in 4-day or longer forecasts. This is particularly true for many of the major weather systems identified in the THORPEX Southern Hemisphere Science Plan, such as major rain events associated with cutoff lows, recurving tropical cyclones, and fire weather events.

The Concordiasi data will be used to perform data assimilation experiments with various observation scenarios to evaluate the potential of the driftsondes to improve the NWP system over the polar areas, and more generally over the Southern Hemisphere. The effect at lower latitudes will be evaluated, in particular, by the Centre for Australian Weather and Climate Research (CAWCR) for both global and regional NWP systems. This will involve both adjoint observation impact calculations (Zhu and Gelaro 2008) and more traditional observing system experiments within the context of a 4DVAR assimilation scheme (Rawlins et al. 2007). The former gives detailed information on the effect of each observation at short (less than 48 hours) forecast ranges, and the latter provides more general information on longer forecast periods.

Lagrangian structures of the flow and data assimilation. The SPB trajectories during Concordiasi will be used to better understand the control exerted by the polar vortex on the motion of air parcels during the process of vortex weakening and breaking. So far, the dispersion of superpressure balloons in the lower stratosphere has been studied with the EOLE dataset (Morel and Bandeen 1973), and it revealed several regimes from exponential dispersion at the smallest scales to superdiffusion in the $100-500-\mathrm{km}$ range and diffusion at larger scales (Lacorata et al. 2004). On the other hand, Joseph and Legras (2002) computed finite-time Lyapunov exponents (FTLEs) on analyzed fields to study the dynamics of the stratospheric vortex. The latter method quantifies the dispersion rates of fluid parcels by measuring the separation between their trajectories after a predetermined finite period. FTLEs have been used to localize areas of maximum expansion and contraction of air parcels, and hence to broadly identify hyperbolic manifolds in the lower stratospheric flow. Hyperbolic invariant manifolds govern the transport and mixing in dynamical systems: stable and unstable manifolds act as repelling and attracting material lines, respectively. When turbulent flows are time dependent, stable and unstable manifolds can intersect in the so-called hyperbolic trajectory. Two fluid parcels initially close to each other on either side of the stable manifold will approach the hyperbolic trajectory and diverge on either side of the unstable manifold after a sufficiently long period of time. Consequently, the invariant manifolds constitute a barrier that fluid particles cannot cross. Preliminary results (de la Cámara et al. 2009) show that two Vorcore superpressure balloons near the edge of the polar vortex-defined by strong potential vorticity (PV) gradients-left the vortex by joining a tongue of vortex air that is ejected out. The tongue of air is a signature of wave breaking. In addition, an intersection of forward and 
backward FTLE maxima-approximately stable and unstable manifolds-is localized over the tongue, indicating the presence of a hyperbolic trajectory. The Concordiasi balloons will provide new opportunities to study these issues in a 3D framework.

There is also significant value of using the Concordiasi flight-level observations from the balloons directly into an assimilation system. There are no satellite wind observations at lower stratospheric levels. [Moderate Resolution Imaging Spectroradiometer (MODIS) winds only reach to about $250 \mathrm{hPa}$.] The Vorcore campaign produced a wind product derived from the balloon tracks at 50 and $70 \mathrm{hPa}$ during the experiment in the southern spring of 2005. The observations are dense enough to have a significant effect on the quality of analyzed wind fields over Antarctica, which in turn can improve ozone transport calculations and the quality of ozone forecasts during the Antarctic vortex breakup. Figure 9 shows the result of assimilating the derived winds from Vorcore into the Goddard Earth Observing System model, version 5 (GEOS-5) 3DVAR assimilation system (Rienecker et al 2007), from 5 September to 19 December 2005. As expected, the RMS difference between analyzed winds and Vorcore winds is greatly reduced. The difference between 6 -h forecasts with and without the Vorcore assimilation shows only a small improvement for the first 60 days, followed by a substantially larger improvement starting around the 61st day (6 November 2005), which is when the polar vortex begins to break down. This indicates that the unsteady (and harder to forecast) nature of the vortex breakdown process benefits from the wind information contained in the balloon trajectories.

Assimilation of winds derived from the balloon trajectories does not make full use of the information contained in them, which is Lagrangian in nature. To get the full effect of Lagrangian data, the balloon positions should themselves be assimilated (Ide et al. 2002). This approach, the so-called Lagrangian data assimilation (LaDA) method, has been applied in ocean data assimilation systems (Salman et al. 2006), and the Vorcore and Concordiasi balloon trajectories represent the first opportunity to demonstrate this technique with an atmospheric data assimilation system. In LaDA, forecasts of the balloon position are made using the wind fields from a global circulation model (GCM). At analysis times (i.e., every six hours), the observed minus forecast (OMF) for the balloon position is used to make corrections to the wind field, either through the evolving background error covariance [for an ensemble Kalman filter (EnKF)] or the adjoint model (for a 4DVAR system). LaDA has been shown to constrain unsteady vortex flows more efficiently than schemes using the derived velocities. The development of Lagrangian assimilation capabilities in both 4DVAR and EnKF is underway at the Global Modeling and Assimilation Office and the University of Maryland.

Ozone depletion, polar stratospheric clouds, and stratospheric dynamics. The ozone layer is an important component of the global environmental system because it protects the biosphere from UV radiation and heats the stratosphere. Each austral spring, the Southern Hemisphere polar stratosphere experiences the largest ozone depletion in Earth's atmosphere. The interannual variability of the Antarctic ozone hole is primarily due to dynamical factors, such as the activity of stratospheric waves that significantly modulate the background stratospheric temperatures and thus the potential for polar stratospheric cloud (PSC) formation. Long-duration balloons deployed during Concordiasi will carry instruments that will provide information on the formation processes of PSCs containing NAT, the longest-lived PSC particle, and on ozone changes along quasi-Lagrangian surfaces. This information is of high relevance to stratospheric processes affecting ozone, and particularly to the links among stratospheric chemistry, dynamics, and cloud microphysics.

Vorcore and previous superpressure balloon flights have shown that mesoscale gravity waves with peri-

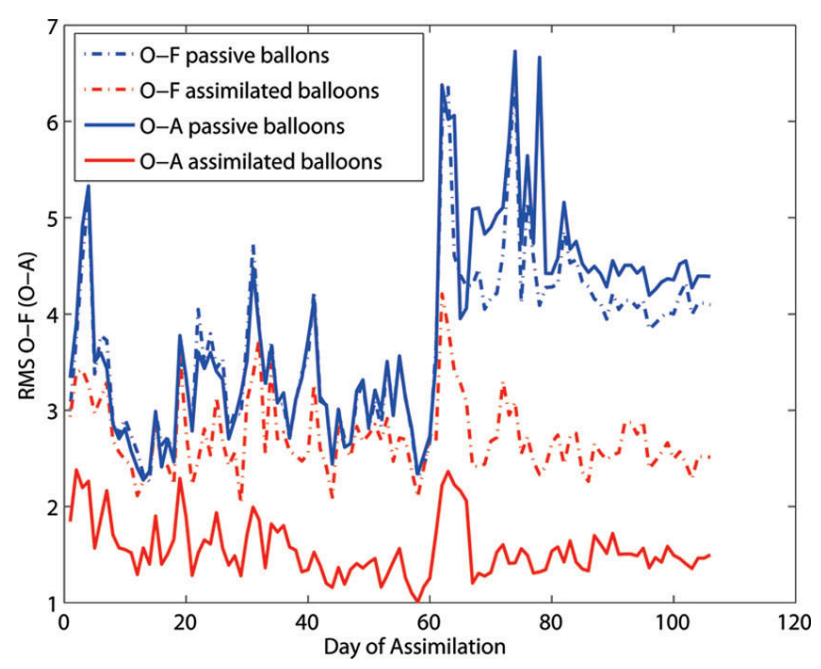

FIG. 9. RMS difference between GEOS-5 analyses (blue lines) or forecasts (red lines) and Vorcore-derived wind observations. The solid lines assimilate all of the usual satellite observations but do not include the balloon data. The dashed lines include both satellite and balloon data. The assimilation period is from 5 Sep (day I) to 19 Dec (day 105) 2005. 
ods longer than one hour can be fully characterized from in situ observations by instruments onboard superpressure balloons (Hertzog et al. 2002). In situ meteorological observations during Concordiasi will be performed more frequently than during Vorcore (1 observation per minute instead of 1 observation per 15 minutes), which will allow for more detailed information on high-frequency gravity waves. Several additional improvements will be made compared with the Vorcore dataset. The accuracy of pressure and temperature observations will also be higher, and the dual-frequency postprocessed GPS will give more precise heights, allowing for the separation of the pressure and height field. This will improve the estimation of gravity wave momentum fluxes, and thus a more accurate characterization of the role played by those waves in driving the middle atmosphere globalscale Brewer-Dobson circulation.

There are still uncertainties in the rates of catalytic reactions involved in ozone depletion: in particular, laboratory estimates of the chlorine monoxide $(\mathrm{ClO})$ dimer photolysis rate significantly disagree, and the most recent ones (Pope et al. 2007) are too small to explain the observed ozone loss with our current knowledge of ozone depletion chemistry (e.g., Frieler et al. 2006; Santee et al. 2008). In conjunction with the meteorological observations previously mentioned, LMD and the University of Colorado are developing small lightweight sensors that are able to perform ozone observations during long-duration flights. Because superpressure balloons approximate the behavior of Lagrangian tracers, at least for a few days, the information gathered along their trajectories will allow for estimates of ozone-loss rates. Observations of temperature, position (and thus solar zenith angle) every minute, and ozone concentration, typically every 10-30 minutes during the flights, will provide strong constraints on the catalytic rates. They will also help to determine the regions in the Antarctic polar vortex where ozone depletion is more likely to occur, such as in the lee side of the Antarctic Peninsula.

Meteorological and chemical observations will be complemented by microphysical measurements. Particle counters designed for PSC measurements will be deployed as companions to four of the ozone sensors. It will thus be possible to get direct Lagrangian information on the links between particle nucleation (especially NAT nucleation) and the temperature history of air parcels. In particular, it will be possible to determine the relative importance of synoptic-scale and mesoscale (gravity wave) cooling on the formation of PSCs, which is still uncertain at the present time.
In the framework of the Concordiasi project, stratospheric ozone assimilation experiments will also be carried out. The operational character of the MetOp mission is an excellent incentive, both for near-real time and operational chemical composition forecasting initiatives (see, e.g., Hollingsworth et al. 2008) and for conducting research on the ozone global budget and its trends over the next 15 years. In this context, the effect of improvements of the atmospheric flow due to the extra Concordiasi observations on the simulations and forecasts of the ozone profile will be assessed using the French chemistry and transport model and assimilation system MOCAGE-PALM, developed in collaboration between CNRM/GAME (Centre National de Recherches Météorologiques/ Groupe d'Etude de l'Atmosphère Météorologique), Laboratoire d'Aérologie, and Centre Européen de Recherche et de Formation Avancée en Calcul Scientifique (CERFACS). This model has the capability to assimilate level-2 (L2) satellite chemical data, generally completed using a variational $3 \mathrm{D}$ technique. MOCAGE-PALM presents several options for the representation of atmospheric chemistry, ranging from cost-efficient linear parameterizations to a comprehensive tropospheric and stratospheric scheme (118 species, including also heterogeneous chemistry processes on PSCs). Good performance has already been obtained with this system (e.g., Geer et al. 2006). Stratospheric ozone data assimilation within Concordiasi will be at very high horizontal and vertical resolution $\left(0.5^{\circ}\right.$, L60 or L90), now available with MOCAGE-PALM. It will provide a significantly better framework with which to represent and quantify chemical and dynamical processes in this region of large horizontal and vertical gradients. The expected advances in meteorological data assimilation and the independent verification data that will be obtained add significant value to this study also. The assimilation system MOCAGE-PALM has already been used to assess the quality of satellite ozone measurements (Massart et al. 2007). It has also proved useful to overcome the possible deficiencies of the model. Ozone analyses obtained with this system have been used in many atmospheric studies in relation with the ozone loss in the Arctic vortex (El Amraoui et al. 2008b), the tropic-midlatitudes exchanges (Bencherif et al. 2007), the stratosphere-troposphere exchanges (Semane et al. 2007), and the exchange between the polar vortex and midlatitudes (El Amraoui et al. 2008a). Preliminary assimilation experiments of total column ozone from IASI [European Organisation for the Exploitation of Meteorological Satellites (EUMETSAT) operational L2 product] have been 
carried out for the period September-October 2008. The results are compared to analyses obtained with the same assimilation system but considering Aura Microwave Limb Sounder (MLS) ozone profiles. An illustration of comparison results between MetOp/ IASI and Aura MLS ozone analyses on the isentropic level $500 \mathrm{~K}$ is given for 12 September 2008 (Fig. 10). With no surprise, a qualitative agreement is found between the two fields, especially concerning the structure of the polar vortex, which is largely driven by the dynamics. However in the MLS product, the vortex is somewhat stronger and the ozone concentrations higher in midlatitudes. Extensive validation of the two assimilation datasets against independent measurements is currently ongoing.

FINAL COMMENTS. The Concordiasi project builds on international collaboration, a combination of innovative measurements and modeling components, and a widespread range of scientific expertise. It focuses on a better analysis and prediction of weather over Antarctica, including clouds and snow accumulation, and on a better understanding of ozone depletion in the polar regions. It is our intention to make a contribution to the objectives of the International Polar Year, which will last long after its end. In particular, it is hoped that the knowledge gained during the experiment will help to make better use of satellite data over the poles, to the benefit of numerical weather prediction, ozone, and climate monitoring.

ACKNOWLEDGMENTS. Concordiasi was built by an international scientific group and is currently supported by the following agencies: Météo-France, CNES, IPEV, PNRA, CNRS/INSU, NSF, UCAR, University of Wyoming, Purdue University, University of Colorado, and ECMWF. The two operational polar agencies PNRA and IPEV are thanked for their support at Concordia station and at the coast of Adélie Land. The NSF is thanked for its support at the McMurdo base. Concordiasi is part of the IPY-THORPEX cluster within the International Polar Year effort. (Detailed information on Concordiasi is available online at www. cnrm.meteo.fr/concordiasi/.)

\section{REFERENCES}

Bencherif, H., L. El Amraoui, N. Semane, S. Massart, D. C. Vidyaranya, A. Hauchecorne, and V.-H. Peuch, 2007: Examination of the 2002 major warming in the southern hemisphere using ground-based and Odin/ SMR assimilated data: Stratospheric ozone distributions and tropic/mid-latitude exchange. Can. J. Phys., 85, 1287-1300.

Boccara, G., A. Hertzog, C. Basdevant, and F. Vial, 2008: Accuracy of NCEP/NCAR reanalyses and ECMWF analyses in the lower stratosphere over Antarctica in 2005. J. Geophys. Res., 113, D20115, doi:10.1029/2008JD010116.

Bouttier, F., and G. Kelly, 2001: Observing-system experiments in the ECMWF $4 \mathrm{D}$-Var data assimilation system. Quart. J. Roy. Meteor. Soc., 127, 1469-1488.

Buizza, R., and T. N. Palmer, 1995: The singular-vector structure of the atmospheric global circulation. J. Atmos. Sci., 52, 1434-1456.

Choudhury, B. J., 1993: Reflectivities of selected land surface types at 19 and $37 \mathrm{GHz}$ from SSM/I observations. Remote Sens. Environ., 46, 1-17.

de la Cámara, C. R. Mechoso, K. Ide, R. Walterscheid, and G. Schubert, 2009: Polar night vortex breakdown and large-scale stirring in the southern stratosphere. Climate Dyn., in press. 
Drobinski, P., and Coauthors, 2006: Des ballons stratosphériques traquent la mousson africaine. $L a$ Météorologie, 55, 2-3.

El Amraoui, L., N. Semane, V.-H. Peuch, and M. L. Santee, 2008a: Investigation of dynamical processes in the polar stratospheric vortex during the unusually cold winter 2004/2005. Geophys. Res. Lett., 35, L03803, doi:10.1029/2007GL031251.

— , V.-H. Peuch, P. Ricaud, S. Massart, D. Cariolle, H. Teyssèdre, and F. Karcher, 2008b: Ozone loss in the 2002-2003 Arctic vortex deduced from the assimilation of Odin/SMR O $\mathrm{O}_{3}$ and $\mathrm{N}_{2} \mathrm{O}$ measurements: $\mathrm{N}_{2} \mathrm{O}$ as a dynamical tracer. Quart. J. Roy. Meteor. Soc., 134, 217-228.

English, S. J., 2008: The importance of accurate skin temperature in assimilating radiances from satellite sounding instruments. IEEE Trans. Geosci. Remote Sens., 46, 403-408.

Farman, J. C., B. G. Gardiner, and J. D. Shanklin, 1985: Large losses of ozone in Antarctica. Nature, 315, 207-210.

Fourrié, N., and F. Rabier, 2004: Cloud characteristics and channel selection for IASI radiances in meteorologically sensitive areas. Quart. J. Roy. Meteor. Soc., 130, 1839-1856.

- D. Marchal, F. Rabier, B. Chapnik, and G. Desroziers, 2006: Impact study of the 2003 North Atlantic THORPEX regional campaign. Quart. J. Roy. Meteor. Soc., 132, 275-295.

Frieler, K., and Coauthors, 2006: Toward a better quantitative understanding of polar stratospheric ozone loss. Geophys. Res. Lett., 33, L10812, doi:10.1029/2005GL025466.

Garrison, J. L., J. S. Haase, B. D. Ventre, E. Calais, M. Sommerville, M. H. Boehme, and S. J. Katzberg, 2005: The GNSS Instrument System for Multistatic and Occultation Sensing (GISMOS) on the High Performance Instrumented Airborne Platform for Environmental Research (HIAPER). GNSSR-05 GNSS Reflections Workshop, University of Surrey, Surrey, United Kingdom.

Geer, A. J., and Coauthors, 2006: The ASSET intercomparison of ozone analyses: Method and first results. Atmos. Chem. Phys., 6, 5445-5474.

Genthon, C., S. Kaspari, and P. A. Mayewski, 2005: Interannual variability of the surface mass balance of West Antarctica from ITASE cores and ERA40 reanalyses, 1958-2000. Climate Dyn., 24, doi:10.1007/ s00382-005-0019-2.

—, G. Krinner, and H. Castebrunet, 2009: Antarctic precipitation and climate-change predictions: Horizontal resolution and margin vs plateau issues. Ann. Glaciol., 50, 55-60.
Grody, N. C., 1988: Surface identification using satellite microwave radiometers. IEEE Trans. Geosci. Remote Sens., 26, 850-859.

Guedj, S., F. Karbou, F. Rabier, and A. Bouchard, 2009: Toward a better modelling of surface emissivity to improve AMSU data assimilation over Antarctica. IEEE Trans. Geosci. Remote Sens., in press.

Hertzog, A., F. Vial, C. R. Mechoso, C. Basdevant, and P. Cocquerez, 2002: Quasi-Lagrangian measurements in the lower stratosphere reveal an energy peak associated with near-inertial waves. Geophys. Res. Lett., 29, 1229, doi:10.1029/2001GL014083.

— duration, superpressure balloons to study the Antarctic lower stratosphere during the 2005 winter. J. Atmos. Oceanic Technol., 24, 2048-2061.

—, G. Boccara, R. A. Vincent, F. Vial, and P. Cocquerez, 2008: Estimation of gravity wave momentum flux and phase speeds from quasi-Lagrangian stratospheric balloon flights. Part II: Results from the Vorcore campaign in Antarctica. J. Atmos. Sci., 65, 3056-3070.

Hollingsworth, A., and Coauthors, 2008: Toward a monitoring and forecasting system for atmospheric composition: The GEMS project. Bull. Amer. Meteor. Soc., 89, 1147-1164.

Hopfner, M., and Coauthors, 2006: MIPAS detects Antarctic stratospheric belt of NAT PSCs caused by mountain waves. Atmos. Chem. Phys., 6, 12211230.

Hoskins, B. J., R. Buizza, and J. Badger, 2000: The nature of singular vector growth and structure. Quart. J. Roy. Meteor. Soc., 126, 1565-1580.

Ide, K., L. Kuznetsov, and C. K. R. T. Jones, 2002: Lagrangian data assimilation for point vortex system. J. Turbul., 3, 1468-5248.

Jones, A. S., and T. H. Vonder Haar, 1997: Retrieval of microwave surface emittance over land using coincident microwave and infrared satellite measurements. J. Geophys. Res., 102 (D12), 13 609-13 626.

Joseph, B., and B. Legras, 2002: Relation between kinematic boundaries, stirring, and barriers for the Antarctic polar vortex. J. Atmos. Sci., 59, 1198-1212.

Karbou, F., and C. Prigent, 2005: Calculation of microwave land surface emissivity from satellite observations: Validity of the specular approximation over snow-free surfaces? IEEE Trans. Geosci. Remote Sens. Lett., 2, 311-314.

,,-- L. Eymard, and J. R. Pardo, 2005: Microwave land emissivity calculations using AMSU measurements. IEEE Trans. Geosci. Remote Sens., 43, 948-959. 
— emissivity and skin temperature for AMSU-A and -B assimilation over land. Quart. J. Roy. Meteor. Soc., 132, 2333-2355.

Krinner, G., O. Magand, I. Simmonds, C. Genthon, and J.-L. Dufresne, 2006: Simulated Antarctic precipitation and surface mass balance at the end of the 20th and 21st centuries. Climate Dyn., 28, 215-230.

Kursinski, E. R., G. A. Hajj, K. R. Hardy, J. T. Schofield, and R. Linfield, 1997: Observing Earth's atmosphere with radio occultation measurements. J. Geophys. Res., 102, 23 429-23 465.

Lacorata, G., E. Aurell, B. Legras, and A. Vulpiani, 2004: Evidence for a $k^{-5 / 3}$ spectrum from the EOLE Lagrangian balloons in the low stratosphere. $J$. Atmos. Sci., 61, 2936-2942.

Larsen, N., and Coauthors, 2004: Formation of solid particles in synoptic-scale Arctic PSCs in early winter 2002/2003. Atmos. Chem. Phys., 4, 2001-2013.

Leutbecher, M., A. Doerenbecher, F. Grazzini, and C. Cardinali, 2004: Planning of adaptive observations during the Atlantic THORPEX regional campaign 2003. ECMWF Newsletter, No. 102, ECMWF, Reading, United Kingdom, 16-25.

Mansfield, D., Richardson, D. and Truscott, B. 2005: An overview of the Atlantic THORPEX Regional Campaign, A-TRec. Proc. THORPEX Science Symp., Montreal, QC, Canada, World Meteorological Organization.

Massart, S., A. Piacentini, D. Cariolle, L. El Amraoui, and N. Semane, 2007: Assessment of the quality of the ozone measurements from the Odin/SMR instrument using model assimilation. Can. J. Phys., 85, 1209-1223.

Matzler, C., 2005: On the determination of surface emissivity from satellite observations. IEEE Trans. Geosci. Remote Sens. Lett., 2, 160-163.

Morel, P., and W. Bandeen, 1973: The EOLE experiment: Early results and current objectives. Bull. Amer. Meteor. Soc., 54, 298-306.

Morland, J. C., D. I. F. Grimes, G. Dugdale, and T. J. Hewison, 2000: The estimation of land surface emissivities at $24 \mathrm{GHz}$ to $157 \mathrm{GHz}$ using remotely sensed aircraft data. Remote Sens. Environ., 73, 323-336.

- - — tions of the microwave emissivity of a semi-arid land surface. Remote Sens. Environ., 77, 149-164.

Plougonven, R., A. Hertzog, and H. Teitelbaum, 2008: Observations and simulations of a largeamplitude mountain wave breaking over the Antarctic Peninsula. J. Geophys. Res., 113, D16113, doi:10.1029/2007JD009739.
Pope, F. D., J. C. Hansen, K. D. Bayes, R. R. Friedl, and S. P. Sander, 2007: The ultraviolet absorption spectrum of chlorine peroxide, ClOOCl. J. Phys. Chem., 111, 4322-4332.

Powers, J. G., A. J. Monaghan, A. M. Cayette, D. H. Bromwich, Y.-H. Kuo, and K. W. Manning, 2003: Real-time mesoscale modeling over Antarctica: The Antarctic Mesoscale Prediction System. Bull. Amer. Meteor. Soc., 84, 1533-1545.

Prigent, C., and W. B. Rossow, 1999: Retrieval of surface and atmospheric parameters over land from SSM/I: Potential and limitation. Quart. J. Roy. Meteor. Soc., 125, 2379-2400.

—_ -, and E. Matthews, 1997: Microwave land surface emissivities estimated from SSM/I observations. J. Geophys. Res., 102, 21 867-21 890.

,$- \ldots$, and —_, 1998: Global maps of microwave land surface emissivities: Potential for land surface characterization. Radio Sci., 33, 745-751.

—, J.-P. Wigneron, W. B. Rossow, and J. R. PardoCarrion, 2000: Frequency and angular variations of land surface microwave emissivities: Can we estimate SSM/T and AMSU emissivities from SSM/I emissivities? IEEE Trans. Geosc. Remote Sens., 38, 2373-2386.

Rabier, F., H. Järvinen, E. Klinker, J.-F. Mahfouf, and A. Simmons, 2000: The ECMWF operational implementation of $4 \mathrm{D}$ variational assimilation. Part I: Experimental results with simplified physics. Quart. J. Roy. Meteor. Soc., 126, 1143-1170.

— related research in data assimilation and observing strategies. Nonlinear Processes Geophys., 15, 81-94.

Rawlins, F., and Coauthors, 2007: The Met Office global four-dimensional variational data assimilation scheme. Quart. J. Roy. Meteor. Soc., 133, 347-362.

Rienecker, M. M., and Coauthors, 2007: The GEOS-5 data assimilation system: A documentation of GEOS-5.0. NASA Tech. Rep. TM-104606, version 27.

Salman, H., L. Kuznetsov, C. K. R. T. Jones, and K. Ide, 2006: A method for assimilating Lagrangian data into a shallow-water equation ocean model. Mon. Wea. Rev., 134, 1081-1101.

Santee, M. L., and Coauthors, 2008: A study of stratospheric chlorine partitioning based on new satellite measurements and modeling. J. Geophys. Res., 113, D12307, doi:10.1029/2007JD009057.

Semane, N., V.-H. Peuch, L. El Amraoui, H. Bencherif, S. Massart, D. Cariolle, J.-L. Attié, and R. Abida, 2007: An observed and analysed stratospheric ozone intrusion over the high Canadian Arctic UTLS region 
during the summer of 2003. Quart. J. Roy. Meteor. Soc., 133, 171-178.

Szunyogh, I., Z. Toth, A. V. Zimin, S. Majumdar, and A. Persson, 2002: Propagation of the effect of targeted observations: The 2000 Winter Storm Reconnaissance Program. Mon. Wea. Rev., 130, 1144-1165.

Tolbert, M. A., and O. B. Toon, 2001: Solving the PSC mystery. Science, 292, 61-63.

Town, M. S., V. P. Walden, and S. G. Warren, 2007: Cloud cover over the South Pole from visual observations, satellite retrievals, and surface-based infrared radiation measurements. J. Climate, 20, 544-559.
Vincent, R. A., A. Hertzog, G. Boccara, and F. Vial, 2007: Quasi-Lagrangian superpressure balloon measurements of gravity-wave momentum fluxes in the polar stratosphere of both hemispheres. Geophys. Res. Lett., 34, L19804, doi:10.1029/2007GL031072.

Weng, F., B. Yan, and N. Grody, 2001: A microwave land emissivity model. J. Geophys. Res., 106 (D17), 20 115-20 123.

Zhu, Y., and R. Gelaro, 2008: Observation sensitivity calculations using the adjoint of the Gridpoint Statistical Interpolation (GSI) analysis system. Mon. Wea. Rev., 136, 335-351.

Zwally, H. J., 1977: Microwave emissivity and accumulation rate of polar firn. J. Glaciol., 18, 195-215.

\section{THE LIFE CY

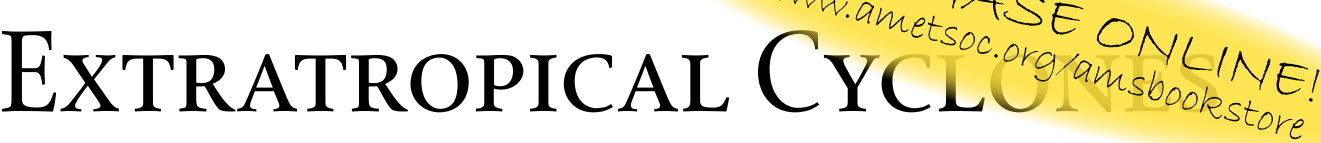

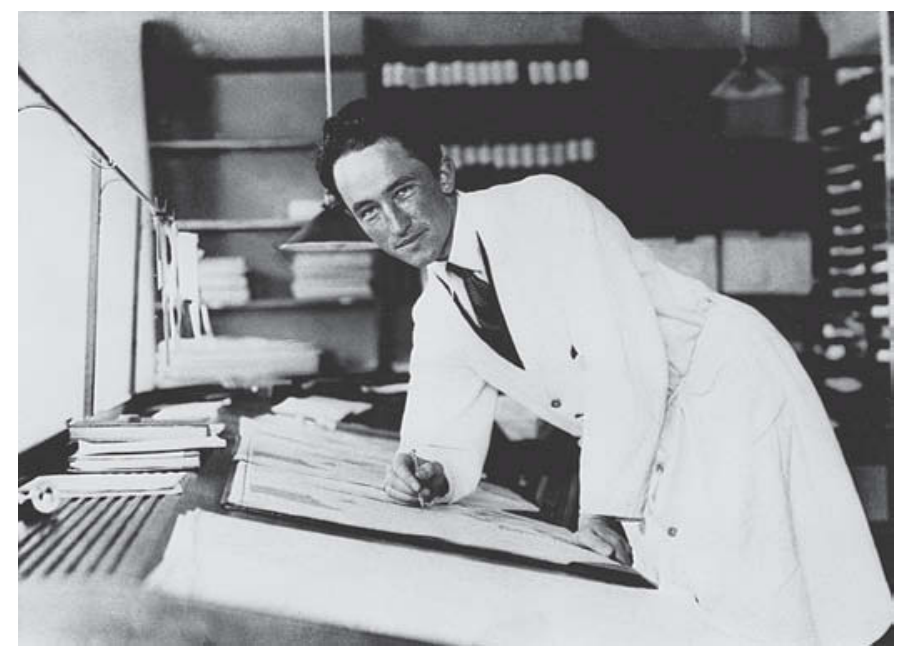

\section{Edited by Melvyn A. Shapiro and Sigbjørn Grønås}

Containing expanded versions of the invited papers presented at the International Symposium on the Life Cycles of Extratropical Cyclones, held in Bergen, Norway, 27 June-1 July 1994, this monograph will be of interest to historians of meteorology, researchers, and forecasters. The symposium coincided with the 75th anniversary of the introduction of Jack Bjerknes's frontal-cyclone model presented in his seminal article, "On the Structure of Moving Cyclones." The monograph's content ranges from a historical overview of extratropical cyclone research and forecasting from the early eighteenth century into the mid-twentieth century, to a presentations and reviews of contemporary research on the theory, observations, analysis, diagnosis, and prediction of extratropical cyclones. The material is appropriate for teaching courses in advanced undergraduate and graduate meteorology.

The Life Cycles of Extratropical Cyclones is available for $\mathbf{\$ 7 5}$ list/\$55 members. Prices include shipping and handling. Please send prepaid orders to Order Department, American Meteorological Society, 45 Beacon St., Boston, MA 02108-3693 or call (617) 227-2426 ext. 686. Visa, MasterCard, or American Express accepted. 